\title{
Short-Term Outcome of Stent Implantation in Saphenous Vein Grafts
} Predictors of Distal Embolization and Restenosis

\author{
Yuzo Kuroda, MD; Kazuhiro Hara, MD; Hiroyoshi Nakajima, MD; Yuji Ikari, MD
}

\begin{abstract}
The present study, which aimed to determine the predictors of distal embolization and restenosis after stenting for vein graft disease, retrospectively analyzed 51 consecutive patients who underwent stent implantation for diseased saphenous vein grafts. Follow-up angiography was performed 6 months after the procedure and the clinical and angiographic variables were analyzed by multivariate logistic regression to determine the predictors of distal embolization and restenosis. Initial clinical success was achieved in 49 patients, 44 of whom underwent follow-up angiography and were enrolled in the retrospective analysis. Distal embolization occurred in 6 grafts (13.6\%). Multivariate analysis showed that the lesion length and the total cholesterol level were independent predictors of distal embolization. Angiographic restenosis occurred in $13(26.5 \%)$ of 49 lesions. The minimum luminal diameter and the percent diameter stenosis after stenting were associated with the occurrence of restenosis. Multivariate analysis of lesions located in the graft body identified graft age as an independent predictor of restenosis. Distal embolization can occur after vein graft stenting, especially in patients with hypercholesterolemia and diffuse stenosis. The post-stenting minimum luminal diameter and the percent diameter stenosis are predictors of restenosis. In particular, graft age is associated with the restenosis of graft body lesions. (Jpn Circ J 2001;
\end{abstract} 65: $265-270$ )

Key Words: Distal embolization; Restenosis; Stent; Vein graft disease

$\mathbf{T}$ he management of patients with vein graft disease after coronary artery bypass surgery poses a difficult problem because repeat bypass surgery is associated with high rates of mortality and morbidity!,2 Percutaneous coronary intervention has an acceptable procedural success rate, but restenosis occurs frequently, with the rate being reported as 40-60\%? The rate of complications and of repeat procedures for recurrence is significantly higher, particularly when the grafts are more than 3 years old4

Recently, stent implantation for saphenous vein graft disease has been performed widely, and several studies have shown that stents may be superior to other methods of treatment5-17 However, the issues of distal embolization after the procedure and of restenosis within the stent remain to be resolved.

We retrospectively analyzed the clinical and angiographic variables of patients who underwent stenting of diseased saphenous vein grafts in order to identify the predictors of distal embolization and restenosis.

\section{Methods}

\section{Patients}

Between August 1990 and March 1999, 51 consecutive patients underwent coronary stent implantation to treat de novo lesions arising in vein grafts more than 3 years old. All patients had significant angiographic diameter stenosis

(Received October 6, 2000; revised manuscript received December 14, 2000; accepted December 19, 2000)

Division of Cardiology, Mitsui Memorial Hospital, Tokyo, Japan

Mailing address: Yuzo Kuroda, MD, Division of Cardiology, Mitsui Memorial Hospital, 1 Kandaizumi-cho, Chiyoda-ku, Tokyo 101-8643, Japan
( $>75 \%$ ) of saphenous vein grafts, and clinical evidence of myocardial ischemia. Patients with acute myocardial infarction or restenosis were excluded from this analysis.

\section{Procedure}

The coronary stents used were Palmaz-Schatz, NIR, and Multi-link stents, with the type of stent being selected at the operators' discretion. In all cases, the lesions were pre-dilated and stents were then implanted according to a standard procedure? In 2 patients, transluminal extraction catheter atherectomy was performed before pre-dilation. In another patient, directional coronary atherectomy was performed for an eccentric lesion before stenting. In all cases, the stents were dilated more than $12 \mathrm{~atm}$ after insertion in order to achieve full expansion and proper apposition. Procedural success was defined as stent implantation in the target lesion with less than $50 \%$ residual stenosis.

\section{Medical Treatment}

All patients were pretreated with oral aspirin (81-162 mg daily). During the procedure, heparin was administered intravenously to maintain an activated clotting time of more than $250 \mathrm{~s}$. After the procedure, patients received warfarin for 1 month (1990-96); after 1996, they received ticlopidine ( $100 \mathrm{mg}$ bid) or cilostazol $(100 \mathrm{mg}$ bid) for 6 months as antithrombotic therapy ${ }^{18}$ All patients continued to receive aspirin indefinitely.

\section{Follow-up}

Clinical success was defined as procedural success without any major hospital complications (ie, death, Q wave myocardial infarction, urgent bypass surgery, or repeat angioplasty). Myocardial infarction was diagnosed if there 
Table 1 Baseline Clinical Characteristics

\begin{tabular}{lc}
\hline \hline & Patients $(n=44)$ \\
\hline Gender $(M / F)$ & $41 / 3$ \\
Age (years) & $66 \pm 6$ \\
Hypertension & $22(50 \%)$ \\
Diabetes mellitus & $18(41 \%)$ \\
Family history & $21(48 \%)$ \\
Smoking & $24(55 \%)$ \\
Total cholesterol $($ mg/dl) & $205 \pm 34$ \\
History of myocardial infarction & $16(36 \%)$ \\
Hemodialysis & $2(5 \%)$ \\
Angina status $(C C S)$ & \\
1 or 2 & $28(64 \%)$ \\
3 or 4 & $16(36 \%)$ \\
Ejection fraction $(\%)$ & $63 \pm 12$ \\
Graft age (years) & $13.0 \pm 3.0$
\end{tabular}

CCS, Canadian Cardiovascular Society.

was elevation of the total creatine kinase level to more than twice the upper limit of normal with a positive MB isoform level of more than 5\%. Clinical follow-up information was obtained from outpatient medical records. Follow-up angiography was done at 6 months after stenting or earlier if clinically indicated.

\section{Analysis of Angiograms}

Quantitative measurement of the target lesion was performed before intervention, immediately after intervention, and at 6 months of follow-up. The projection showing the most severe stenosis before intervention was selected for measurement of the minimum luminal diameter (MLD) and reference diameter using an automated edge-detection coronary measurement system (Cathex Coronary Image Processor-310, Cathex, Inc, Tokyo, Japan) ${ }^{18}$

Distal embolization was defined as the presence of a new filling defect or abrupt cutoff in one of the distal coronary artery branches after stenting of the target lesion. ${ }^{19}$ Angiographic restenosis at the stented site was defined as the presence of more than $50 \%$ diameter stenosis (DS) at 6 months of follow-up.

\section{Statistical Analysis}

Continuous variables were expressed as the mean \pm SD and categorical variables were expressed as percentages. Clinical and angiographic variables were compared between the patients with and without restenosis of the target lesion. A similar comparison was performed between patients with and without distal embolization. In this analysis, lesion length was calculated as the sum of the total length of all lesions if multiple lesions were treated in a single graft. Student's t test was used for comparison of continuous variables, and either chi-square analysis or Fisher's exact test was used for comparison of categorical variables. Predictors of distal embolization and restenosis were determined by multivariate logistic regression analysis using SAS 6.12 software (SAS Institute Inc, NC, USA). Variables with a p value of less than 0.2 on univariate analysis were entered into the multivariate analysis. A p value of less than 0.05 was considered to indicate statistical significance.

\section{Results}

Clinical Outcome

Of the 51 patients who underwent stent implantation in
Table 2 Baseline Lesion Characteristics

\begin{tabular}{lc}
\hline \hline & Lesions $(n=49)$ \\
\hline SVG location & \\
LAD & $14(28.6 \%)$ \\
Cx & $27(55.1 \%)$ \\
Lesion location & $8(16.3 \%)$ \\
Aorto-ostial segment & \\
Body & $10(20.4 \%)$ \\
Distal anastomosis & $34(69.4 \%)$ \\
Lesion length $($ mm) & $5(10.2 \%)$ \\
Reference diameter $(\mathrm{mm})$ & $15.3 \pm 7.9$ \\
Minimal lumen diameter $(\mathrm{mm})$ & $3.66 \pm 0.76$ \\
\hline
\end{tabular}

$S V G$, saphenous vein graft; LAD, left anterior descending; $C x$, circumflex; $R C A$, right coronary artery.

saphenous vein grafts, initial procedural success was achieved in 49 . In 1 patient, stent delivery was unsuccessful; in the other, subacute thrombosis of the stent occurred on the next day, resulting in non-Q wave myocardial infarction, and repeat angioplasty of the occluded site was performed. Thus, the clinical success rate was $96 \%$.

Of the 49 patients with clinical success, 1 patient died of peritonitis 4 months after stenting. In 2 patients, follow-up angiography was not performed for clinical reasons, and 2 other patients were not followed at the admitting institution. As a result, follow-up angiograms were obtained in 44 patients, and these were subjected to retrospective analysis.

Baseline clinical characteristics are listed in Table 1. The ejection fraction was well preserved in the majority of patients. The treated grafts were relatively old, with a mean graft age of $13.0 \pm 3.0$ years.

\section{Baseline Angiography}

A total of 49 lesions were treated in the 44 patients; multiple lesions affecting a single graft were treated in 5 patients. Baseline lesion characteristics are shown in Table 2. The lesion was located at the aorto-ostial segment of the graft in 10 cases, the body in 34 cases, and the distal anastomosis in 5 cases. The average reference diameter was $3.66 \pm 0.76 \mathrm{~mm}$ and the average lesion length was $15.3 \pm 7.9$ $\mathrm{mm}$ (12 lesions were longer than $20 \mathrm{~mm}$ ). There were no totally occluded grafts.

\section{Procedure}

Palmaz-Schatz stents were used for 38 lesions, Multi-link stents for 6 lesions, and a NIR stent for 1 lesion. Two types of stents were implanted in the other 4 lesions (hybrid stenting). A mean of $1.2 \pm 0.5$ stents were implanted, with multiple stents being needed to cover the full length of 11 lesions. The average balloon diameter and the pressure for post-dilation was $3.84 \pm 0.60 \mathrm{~mm}$ and $14.8 \pm 3.8 \mathrm{~atm}$, respectively. The MLD increased from $1.13 \pm 0.51 \mathrm{~mm}$ before treatment to $3.03 \pm 0.76 \mathrm{~mm}$ after stenting.

Distal embolization occurred in 6 of the 44 patients treated by stenting (13.6\%). In 1 case, the main trunk of the left circumflex artery was embolized after balloon inflation, and non-Q wave myocardial infarction occurred with elevation of the creatine kinase level to $427 \mathrm{U} / \mathrm{L}$. In the other 5 cases, embolization affected small distal branches without any significant elevation of creatine kinase.

\section{Follow-up Angiography}

Follow-up angiography was performed at a mean of 
Table 3 Quantitative Lesion Analysis

\begin{tabular}{lcccc}
\hline \hline & $\begin{array}{c}\text { Overall } \\
(n=49)\end{array}$ & $\begin{array}{c}\text { Aorto-ostial } \\
(n=10)\end{array}$ & $\begin{array}{c}\text { Body } \\
(n=34)\end{array}$ & $\begin{array}{c}\text { Distal anastomosis } \\
(n=5)\end{array}$ \\
\hline $\begin{array}{l}\text { Lesion length }(\mathrm{mm}) \\
\text { Reference diameter }(\mathrm{mm})\end{array}$ & $15.3 \pm 7.9$ & $14.4 \pm 8.9$ & $16.3 \pm 7.1$ & $10.1 \pm 10.3$ \\
Minimal lumen diameter $(\mathrm{mm})$ & $3.66 \pm 0.76$ & $3.41 \pm 0.83$ & $3.74 \pm 0.77$ & $3.66 \pm 0.61$ \\
$\quad$ Pre & $1.13 \pm 0.51$ & $1.02 \pm 0.63$ & $1.20 \pm 0.88$ & $0.88 \pm 0.42$ \\
Post & $3.03 \pm 0.60$ & $2.77 \pm 0.56$ & $3.16 \pm 0.55$ & $2.68 \pm 0.79$ \\
$\quad$ Follow-up & $2.17 \pm 0.96$ & $1.79 \pm 0.95$ & $2.34 \pm 0.89$ & $1.79 \pm 1.34$ \\
Restenosis & $13(26.5 \%)$ & $4(40.0 \%)$ & $7(20.6 \%)$ & $2(40.0 \%)$ \\
\hline
\end{tabular}

Table 4 Predictors of Restenosis

\begin{tabular}{|c|c|c|c|c|c|}
\hline & \multirow{2}{*}{ Restenosis } & \multirow{2}{*}{ No restenosis } & \multirow{2}{*}{$\begin{array}{l}\text { Univariate analysis } \\
\text { p value }\end{array}$} & \multicolumn{2}{|c|}{ Multivariate analysis } \\
\hline & & & & OR & $p$ value \\
\hline Overall lesions & $(n=13)$ & $(n=36)$ & & & \\
\hline Total cholesterol $(\mathrm{mg} / \mathrm{dl})$ & $185 \pm 25$ & $212 \pm 33$ & 0.017 & & \\
\hline Graft age (years) & $14.2 \pm 2.8$ & $12.4 \pm 2.8$ & 0.064 & & \\
\hline Balloon diameter $(\mathrm{mm})$ & $3.60 \pm 0.57$ & $3.93 \pm 0.59$ & 0.090 & & \\
\hline Post-MLD $(\mathrm{mm})$ & $2.53 \pm 0.45$ & $3.20 \pm 0.55$ & 0.002 & $0.153 *$ & 0.024 \\
\hline Post-\%DS (\%) & $28.2 \pm 13.9$ & $11.4 \pm 13.3$ & 0.002 & $1.074 * *$ & 0.026 \\
\hline Body lesions & $(n=7)$ & $(n=27)$ & & & \\
\hline Total cholesterol $(\mathrm{mg} / \mathrm{dl})$ & $186 \pm 21$ & $213 \pm 36$ & 0.070 & & \\
\hline Graft age (years) & $15.2 \pm 3.2$ & $11.9 \pm 2.8$ & 0.025 & $1.553 * * *$ & 0.025 \\
\hline Post-MLD $(\mathrm{mm})$ & $2.73 \pm 0.52$ & $3.26 \pm 0.52$ & 0.033 & & \\
\hline Post-\%DS (\%) & $25.5 \pm 14.3$ & $11.0 \pm 14.0$ & 0.036 & & \\
\hline
\end{tabular}

Only variables with $p$ value of less than 0.20 on the univariate analysis are presented and these variables were entered into the multivariate logistic regression analysis. MLD, minimal lumen diameter; \%DS, percent diameter stenosis; OR, odds ratio. *per $1 \mathrm{~mm}$ increase, **per $1 \%$ increase, ***per 1 year increase.

Table 5 Predictors of Distal Embolization

\begin{tabular}{|c|c|c|c|c|c|}
\hline & \multicolumn{2}{|c|}{ Embolization } & \multirow{2}{*}{$\begin{array}{l}\text { Univariate analysis } \\
\text { p value }\end{array}$} & \multicolumn{2}{|c|}{ Multivariate analysis } \\
\hline & $(+)(n=6)$ & $(-)(n=38)$ & & OR & $p$ value \\
\hline Total cholesterol $(\mathrm{mg} / \mathrm{dl})$ & $238 \pm 47$ & $200 \pm 28$ & 0.019 & $1.046^{*}$ & 0.011 \\
\hline Balloon diameter (mm) & $4.42 \pm 0.49$ & $3.78 \pm 0.59$ & 0.029 & & \\
\hline Balloon pressure (atm) & $12.3 \pm 3.7$ & $15.5 \pm 3.3$ & 0.054 & & \\
\hline Lesion length $(\mathrm{mm})$ & $24.8 \pm 13.5$ & $15.8 \pm 8.4$ & 0.050 & $1.131 * *$ & 0.044 \\
\hline
\end{tabular}

Only variables with $p$ value of less than 0.20 on the univariate analysis are presented and these variables were entered into the multivariate logistic regression analysis. OR, odds ratio. *per $1 \mathrm{mg} /$ dl increase, **per $1 \mathrm{~mm}$ increase.

$183 \pm 41$ days after the initial procedure. The results of the quantitative lesion analysis are summarized in Table 3 . The mean MLD and \%DS at follow-up were $2.17 \pm 0.96 \mathrm{~mm}$ and $41 \pm 24 \%$, respectively.

The overall incidence of restenosis was $26.5 \%$. Occlusion of the target lesion occurred in 2 cases $(4.1 \%)$. The incidence of restenosis affecting the graft body was $21 \%$. The restenosis rates for the aorto-ostial and distal anastomotic sites tended to be higher than for the graft body, although this difference did not achieve statistical significance.

The baseline clinical and angiographic characteristics of the lesions with and without restenosis are summarized in Table 4. Clinical variables included age, gender, hypertension, diabetes mellitus, family history, smoking, total cholesterol level, history of myocardial infarction, hemodialysis, graft age, and use of cilostazol. Angiographic and procedural variables included lesion length, reference diameter, preMLD, post-MLD, post-\%DS, multiple stenting, post-dilation balloon diameter, and post-dilation pressure. The total cholesterol level was lower and the graft tended to be older in the lesions with restenosis. The average diameter of the balloon used for post-dilation tended to be greater for lesions without restenosis. MLD after stenting was significantly smaller in the lesions with restenosis, and \%DS after stenting was greater in the lesions with restenosis. There was no significant difference between both groups with respect to lesion length, reference diameter, and pre-treatment MLD.

Multivariate logistic regression analysis identified 2 variables as independent predictors of restenosis: (1) MLD after stent implantation (odds ratio (OR) 0.153 per $1 \mathrm{~mm}$ increase, $p=0.024)$ and (2) \%DS after stent implantation (OR 1.074 per $1 \%$ increase, $\mathrm{p}=0.026$ ).

Because there was a trend toward a lower restenosis rate when lesions were located in the graft body compared with those located at the anastomoses, the same univariate and multivariate analysis was performed for graft body lesions alone to determine the predictors of restenosis (Table 4). The mean total cholesterol level tended to be lower and the graft age was older in the lesions with restenosis. MLD after stent implantation was smaller for the lesions with restenosis than for those without restenosis. The post-treatment \%DS was greater for the lesions with restenosis than for those without restenosis.

Multivariate logistic regression analysis identified graft 
age as the only independent predictor of restenosis for lesions located in the graft body (OR 1.553 per 1 year increase, $p=0.025)$. To assess the potential relationship between graft age and other baseline angiographic data, Pearson's correlation coefficients were calculated, and a tendency for a smaller MLD and a greater \%DS after stenting was observed in older grafts, but these trends were not statistically significant $(R=-0.327: p=0.059, R=0.314$ : $\mathrm{p}=0.070$, respectively).

The baseline characteristics of the patients with and without distal embolization are summarized in Table 5. The mean total cholesterol level was higher in the patients with distal embolization. The patients with embolization had longer lesions than those without embolization. The average balloon diameter was larger, and the post-dilation pressure tended to be lower in the embolization group.

Multivariate logistic regression analysis revealed 2 variables that were independent predictors of distal embolization: (1) total cholesterol level (OR 1.046 per $1 \mathrm{mg} / \mathrm{dl}$ increase, $\mathrm{p}=0.011)$ and (2) lesion length (OR 1.131 per $1 \mathrm{~mm}$ increase, $\mathrm{p}=0.044$ ).

\section{Discussion}

Coronary artery bypass graft surgery effectively relieves angina in patients with coronary heart disease ${ }^{20}$ and in particular, in patients with multivessel coronary artery disease, bypass surgery can provide a better clinical outcome than percutaneous coronary angioplasty. ${ }^{21}$ However, atherosclerosis develops in the grafts from about 3 years after the bypass operation ${ }^{22-24}$ and only approximately $60 \%$ of saphenous vein grafts remain patent at 10-12 years after surgery because of the progression of atherosclerotic disease. 25,26

Repeat bypass surgery is technically more difficult to perform and is associated with a relatively high mortality rate $(3-6.5 \%)$ and a high perioperative myocardial infarction rate (3.4-11.5\%), and the likelihood of complete relief of symptoms is less than with the initial operation!,2 Percutaneous balloon angioplasty of stenotic vein grafts can be performed with an initial success rate of $90 \%$, but is associated with a relatively high restenosis rate?

Two randomized studies have shown that coronary stenting reduces the restenosis rate in native coronary arteries compared with balloon angioplasty,27,28 and several observational studies have indicated that stenting of saphenous vein grafts is associated with a relatively lower incidence of restenosis (17-30\%) than conventional balloon angioplasty? ${ }^{76}$ A randomized trial showed that stent implantation is associated with a better clinical outcome than balloon angioplasty, although there was no significant difference in the angiographic restenosis rate ${ }^{17}$

Another problem with the treatment of saphenous vein graft stenosis is distal embolization, with the reported incidence following balloon angioplasty ranging from 3 to $7 \%$ ? Whether stenting of saphenous vein grafts decreases the incidence of distal embolization or not remains controversial.

\section{Distal Embolization}

Distal embolization occurred in $13.6 \%$ of all patients in the present study, a frequency that was higher in comparison with previous reports $3,6,7,11,12$ The reason for this relatively high frequency of distal embolization is unclear, but may have been related to the longer lesion length and higher post-dilation pressure (mean: $14.8 \mathrm{~atm}$ ). In fact, lesion length was associated with the occurrence of distal embolization on multivariate analysis. Liu et al also reported that a diffuse lesion and large plaque volume were independent predictors of distal embolization. ${ }^{2}$ Particulate debris is reported to predominantly consist of soft acellular atheromatous material 19 of which diffuse stenoses contain a large volume and so dilation of diffuse lesions could be associated with dislodgement of the soft and friable atheromatous matrix, resulting in a higher frequency of distal embolization.

Whether a high post-dilation pressure increases the probability of dislodging plaque material is unclear. In the present study, all of the lesions were treated with a high post-dilation pressure of more than $12 \mathrm{~atm}$ and comparison between pressure less than $12 \mathrm{~atm}$ and high pressure was not available. Stent implantation is expected to reduce the frequency of distal embolization by entrapping the atheromatous plaque, but a high post-dilation pressure may precipitate the dislodgement of atheromatous plaque through the stent struts. Whether less aggressive post-dilation would be better after vein graft stenting remains to be elucidated.

The total cholesterol level was also associated with the occurrence of distal embolization in our study. Hyperlipidemia is related to the progression of vein graft stenosis and hyperlipidemic patients have more severe luminal narrowing of vein grafts $23,25,30$ In hyperlipidemic patients, atheromatous plaque may contain more friable material, which may cause plaque disruption and embolization after lesion dilation.

\section{Restenosis}

The incidence of restenosis was $26.5 \%$ in our series, which was lower than the reported incidence of restenosis after conventional balloon angioplasty for saphenous vein grafts, and comparable with previous reports on vein graft stenting? ${ }^{7-17}$ The restenosis rate tended to be higher if the lesion was located in the ostial segment or at the distal anastomosis. Eeckhout et al also reported a higher rate of restenosis for lesions at the proximal and distal anastomosis.2 The same trend was also observed with conventional balloon angioplasty of ostial lesions? This may be because the aortic wall is included in the narrowed ostial segment and is resistant to balloon dilation, resulting in a smaller lumen after dilation. On the other hand, another report on conventional balloon angioplasty of vein grafts showed that the restenosis rate for distal anastomosis lesions was lower than that for graft body lesions? An observational study comparing balloon angioplasty and stenting at the distal anastomosis reported a similar clinical outcome in both groups ${ }^{31}$ although the late angiographic restenosis rate was not calculated in that study. Our higher restenosis rate at the distal site may be attributable to the discrepancy in reference diameter between the graft and the native artery, which makes it difficult to decide on the optimal stent size and to achieve full expansion and proper stent apposition. Because conventional balloon angioplasty can achieve a favorable clinical and angiographic outcome, stenting may not always be necessary for lesions at the distal anastmosis.

Mutivariate analysis showed that the MLD and \%DS after stenting were associated with restenosis, which are consistent with results for stenting in native coronary arteries.7 The independent predictor of restenosis in graft body lesions was graft age, a relationship that has never been addressed in previous reports on vein graft stenting, possibly because the graft age has been 'younger' in previous studies (5-9 years on average), whereas the present study included 
older grafts and the mean graft age was 13 years. As vein grafts get older, atherosclerotic lesions progress to more diffuse stenosis 25,26 Although there was no significant correlation, MLD tended to be smaller and \%DS tended to be greater after stenting of older grafts. These results imply that older vein graft stenoses may be refractory to balloon dilation, even when stenting is done with a high post-dilation pressure, because of the presence of diffusely progressive atherosclerosis.

The reason why predictors of restenosis were different between the analysis for overall lesions and that for body lesions is unclear. However, it is reasonable to suppose that the lesions were resistant to balloon dilation, especially in the ostial segment, and that the influence of post-stenting lumen diameter on the occurrence of restenosis is greater than in other segments, resulting in a significant association between MLD, or \%DS, and restenosis in the analysis for the overall lesions. It may be because of the small number in the analysis for the body lesions that MLD and \%DS did not prove to be significant predictors of restenosis.

\section{Study Limitations}

First, the number of patients was relatively small, which may have made it impossible to detect other predictive factors for distal embolization or restenosis. Second, several types of stents were used and the different stent designs might have affected the results, but because of the small number of patients, comparison between different stent types was impossible. Third, as only de novo lesions were included, these results cannot be extrapolated to vein graft restenosis. Fourth, the restenosis rate was only evaluated at 6 months after stent implantation. However, the time course of restenosis in vein graft lesions has been reported to be longer than this, 3 so we could not evaluate the occurrence of 'late restenosis'. Fifth, there were 3 patients who were pre-treated with atherectomy devices before stenting and whether this affected the occurrence of restenosis or distal embolization remains unclear. Again, because of the small number of patients, the effect of atherectomy could not be evaluated in this study.

\section{Conclusion}

Stenting of saphenous vein graft stenoses achieves a high procedural success rate. Distal embolization may occur, especially in patients with diffuse lesions and hypercholesterolemia, but it is not usually associated with major adverse cardiac events. The restenosis rate is also acceptable. Poststenting luminal diameter and percent diameter stenosis are factors that can predict restenosis, and it is important to obtain as larger a lumen as possible after stenting. Graft age is a predictive factor for restenosis of graft body lesions. An effective method for treating old, diffusely diseased and degenerated vein graft stenoses has not yet been established, so further investigation into the treatment of the vein graft disease is necessary.

\section{Acknowledgment}

We thank Professor Tetsu Yamaguchi, Third Department of Internal Medicine, Toho University School of Medicine, for his valuable and helpful suggestions.

\section{References}

1. Schaff HV, Orzulak TA, Gersh BJ, Pieher JM, Puga FJ, Dainelson
GK, et al: The morbidity and mortality of re-operation for coronary artery disease and analysis of late results with use of actuarial estimate of event-free interval. J Thorac Cardiovasc Surg 1983; 85: 508-515

2. Cameron A, Kemp HG, Green GE: Reoperation for coronary artery disease. Circulation 1988; 78(SupplI): I-158-I-162

3. de Feyter PJ, van Suylen RJ, de Jaegere PPT, Topol EJ, Serruys PW: Balloon angioplasty for the treatment of lesions in saphenous vein bypass grafts. J Am Coll Cardiol 1993; 21: 1539-1549

4. Platko WP, Hollman J, Whitlow PL, Franco I: Percutaneous transluminal angioplasty of saphenous vein graft stenosis: Long-term follow-up. J Am Coll Cardiol 1989; 14: 1645-1650

5. Wong SC, Popma JJ, Pichard AD, Kent KM, Satler LF, Mintz GS, et al: Comparison of clinical and angiographic outcomes after saphenous vein graft angioplasty using coronary versus 'biliary' tubular slotted stents. Circulation 1995; 91: 339-350

6. White CJ, Ramee SR, Collins TJ, Escobar A, Jain SP: Placement of 'biliary' stents in saphenous vein coronary bypass grafts. Cathet Cardiovasc Diagn 1993; 30: $91-95$

7. Wong SC, Baim DS, Schatz RA, Teirstein PS, King SB, Curry RC, et al: Immediate results and late outcomes after stent implantation in saphenous vein grafts lesions: The multicenter US Palmaz-Schatz stent experience. J Am Coll Cardiol 1995; 26: 704-712

8. Urban P, Sigwart U, Golf S, Kaufmann U, Sadeghi H, Kappenberger L: Intravascular stenting for stenosis of aortocoronary venous bypass grafts. J Am Coll Cardiol 1989; 13: 1085-1091

9. Piana RN, Moscucci M, Cohen DJ, Kugelmass AD, Senerchia C, Kuntz R, et al: Palmaz-Schatz stenting for treatment of focal vein graft stenosis: Immediate results and long-term outcome. $J$ Am Coll Cardiol 1994; 23: 1296-1304

10. Fenton SH, Fischman DL, Savage MP, Schatz RA, Leon MB, Baim DS, et al: Long-term angiographic and clinical outcome after implantation of balloon-expandable stents in aortocoronary saphenous vein grafts. Am J Cardiol 1994; 74: 1187-1191

11. de Scheerder IK, Strauss BH, de Feyter PJ, Beatt KJ, Baur LHB, Wijns W, et al: Stenting of venous bypass grafts: A new treatment modality for patients who are poor candidate for reintervention. Am Heart J 1992; 123: 1046-1054

12. Eeckhout E, Goy JJ, Stauffer JC, Vogt P, Kappenberger L: Endoluminal stenting of narrowed saphenous vein grafts: Long-term clinical and angiographic follow-up. Cathet Cardiovasc Diagn 1994; 32: $139-146$

13. Strumpf RK, Mehta SS, Ponder R, Heuser RR: Palmaz-Schatz stent implantation in stenosed saphenous vein grafts: Clinical and angiographic follow-up. Am Heart J 1992; 123: 1329-1336

14. Jaegere PP, van Domburg RT, de Feyter PJ, Ruygrok PN, van der Giessen WJ, van den Brand MJ, et al: Long-term clinical outcome after stent implantation in saphenous vein grafts. $J$ Am Coll Cardiol 1996; 28: 89-96

15. Strauss BH, Serruys PW, Bertrand ME, Puel J, Goy JJ, Kappenberger L, et al: Quantitative angiographic follow-up of the coronary Wallstent in native vessels and bypass grafts (European experience - March 1986 to March 1990). Am J Cardiol 1992; 69: 475-481

16. Brener SJ, Ellis SG, Hansen CA, Leon MB, Topol EJ: Comparison of stenting and balloon angioplasty for narrowing in aortocoronary saphenous vein conduits in place more than five years. Am J Cardiol 1997; 79: $13-18$

17. Savage MP, Douglas JS, Fischman DL, Pepine CJ, King SB, Werner JA, et al: Stent placement compared with balloon angioplasty for obstructed coronary bypass grafts. N Engl J Med 1997; 337: 740-747

18. Yamasaki M, Hara K, Ikari Y, Kobayashi N, Kozuma K, Ohmoto Y, et al: Effects of cilostazol on late lumen loss after Palmaz-Schatz stent implantation. Cathet Cardiovasc Diagn 1998; 44: 387-391

19. Webb JG, Carere RG, Virmani R, Baim D, Teirstein PS, Whitlow P, et al: Retrieval and analysis of particulate debris after saphenous vein graft intervention. J Am Coll Cardiol 1999; 34: 468-475

20. Okada M, Matsuda S, Kozawa S, Yasuoka S, Ogawa K, Nakamura K: Long-term results and its management after coronary bypass surgery. Jpn Circ J 1986; 50: 888-894

21. Hara K, Suma H, Kozuma K, Horii T, Wanibuchi Y, Yamaguchi T, et al: Long-term outcome of percutaneous transluminal coronary angioplasty and coronary bypass surgery for multivessel coronary artery disease. Jpn Circ J 1996; 60: 940-946

22. Batayias GE, Barboriak JJ, Korns ME, Pintar K: The spectrum of pathologic changes in aortocoronary saphenous vein grafts. Circulation 1977; 56(Suppl II): II-18 - II-22

23. Lie JT, Lawrie GM, Morris GC: Aortocoronary bypass sapheous vein grafts atherosclerosis: Anatomic study of 99 vein grafts from normal and hyperlipoproteinemic patients up to 75 months postoperatively. Am J Cardiol 1977; 40: 906-914

24. Smith SH, Geer JC: Morphology of saphenous vein-coronary artery 
bypass grafts: Seven to 116 months after surgery. Arch Pathol Lab Med 1983; 107: 13-18

25. Bourassa MG, Enjalbert M, Campeau L, Lesperance J: Progression of atherosclerosis in coronary arteries and bypass grafts: Ten years later. Am J Cardiol 1984; 53: 102C-107C

26. Fitzgibbon GM, Leach AJ, Kafka HP, Keon WJ: Coronary bypass graft fate: Long-term angiographic study. J Am Coll Cardiol 1991; 17: $1075-1080$

27. Fischman DL, Leon MB, Baim DS, Schatz RA, Savage MP, Penn I, et al: A randomized comparison of coronary-stent placement and balloon angioplasty in the treatment of coronary artery disease. $N$ Engl J Med 1994; 331: 496-501

28. Serruys PW, de Jaegere P, Kiemeneij F, Macaya C, Rutsch W, Heyndrickx G, et al: A comparison of balloon-expandable-stent implantation with balloon angioplasty in patients with coronary artery disease. $N$ Engl J Med 1994; 331: 489-495

29. Liu MW, Douglas JS, Lembo NJ, King SB: Angiographic predictors of a rise in serum creatine kinase (distal embolization) after balloon angioplasty of saphenous vein coronary artery bypass grafts. Am J Cardiol 1993; 72: 514-517

30. Campeau L, Enjalbert M, Lesperance J, Bourassa MG, Kwiterrovich $\mathrm{P}$, Wacholder S, et al: The relation of risk factors to the development of atherosclerosis in saphenous-vein bypass grafts and the progression of disease in the native circulation. N Engl J Med 1984; 311: $1329-$ 1332

31. Gruberg L, Hong MK, Mehran R, Mintz GS, Kornowski R, Lansky $\mathrm{AJ}$, et al: In-hospital and long-term results of stent deployment compared with balloon angioplasty for treatment of narrowing at the sapheous vein graft distal anastomosis site. Am J Cardiol 1999; 84: $1381-1384$ 